\title{
THE IMPORTANCE OF ETHNOGRAPHIC RESEARCH IN TEXTILE DESIGN
}

\author{
Banu H. Gürcüm ${ }^{1}$, Pınar Arslan² \\ ${ }^{1}$ Assoc. Prof., Gazi University, Turkey, banugurcum@gmail.com \\ ${ }^{2}$ Res. Asst., Gazi University, Turkey, pinar-arslan@windowslive.com
}

\begin{abstract}
Etymologically, ethnography comes from the Greek words ethnos (nation, people) and graphia (writing) and means therefore a written presentation of a people or a population and seeks to identify and interpret its universal traits. With its roots in cultural anthropology, ethnography focuses on small-scale societies and the original central concept remains within the meaning of culture. In anthropology, ethnography developed a way to explore the everyday realities of people living in small scale, non-western societies and to make understandings of those realities explicit and available to others. The approach relied on the ability of all humans to figure out what is going on through participation in social life. The techniques ethnographers use follow the routine of the everyday life. Thus the research techniques and strategies of ethnography developed and evolved over the years to provide ways for the ethnographer to "be present" for the mundane, the exceptional, and the extraordinary events in people's lives. With the advent of postmodernism, ethnographic perspective became a valuable tool in the design of new technologies. This has presented a new set of challenges for designers as they design and built applications that leverage powerful, digital technologies for use by people of all societies and cultures. The field of design has been an adjunct to art and craft and in a postmodern context. With the transformation of design into an industrial discipline came responsibilities that the field of design studies has only recently begun to address methodologies. Design is now becoming a generalizable discipline that may as readily be applied to processes, interfaces. To understand design as a discipline that can function within any of these frames means developing a general theory of design. From methodological perspective there is no solid theoretical framework which can assist the craftsman or the novice textile designer to consciously integrate their culture in designing products. For this reason this paper challenges designers to gain a deeper understanding of the importance of ethnographic research in textile design and explain qualitative techniques that can be used in ethnographic researches for textile design, searching for meaning in socially constructed reality or a traditional context.
\end{abstract}

Keywords: Ethnographic research, textile design, design science research

\section{INTRODUCTION}

The term design denotes a process interested in finding a solution with the help of know-how, ingenuity, good memory, pattern recognition abilities, search in the solution space, lateral thinking, brainstorming, analogies (Evbuomwan et al, 1996, p.302). Cross (1999, p.5) mentioned that unlike animals and machines, designing was a natural human ability. He also expressed it as the highest form of human intelligence (2006, p.34). Some researchers including Friedman (2000, p.13) argued that design was a process rooted in and involved in both theoretical disciplines and fields of practice. Terzidis confirmed that design was often confused with planning 
although it differed. He defined planning as the act of devising a scheme, program or method worked out beforehand for the accomplishment of an objective, and design as a conceptual activity involving formulating an idea intended to be expressed in a visible form or carried into action (Terzidis, 2007, p.69). Stolterman (2008, p.11) mentioned that design was for the designer a pragmatic and situational process, which never cared for the "correct" way of doing things. According to him design was all about "what one could use to reach his purpose". Design is about conceptualization, imagination, and interpretation. Rather than indicating a course of action specific for the accomplishment of a task, design is a vague, ambiguous, and indefinite process of genesis, emergence, or formation, of something to be executed, but whose starting point, origin, or process often are certain (Terzidis, 2007, p.69).

As a result of being applied to processes and interfaces, designers can easily generalize design discipline by developing a general theory of design. Alexander (1964, p.77) concluded that in present design practice, the most critical step was during which the problem was prepared and translated into design. He expressed that finding the solution to a design problem always depended on some kind of intuition since design was by nature imaginative and inspirational.

Many researchers including Moalosi et al (2007) concluded about the lack of in-depth research and appropriate methods to assist designers on how culture could be consciously integrated in product design (Onibere et al, 2001; Hugo, 2002; Kotro and Pantzar, 2002 and Aykin, 2005). When the concern is design within cultural aspects current design approaches with their standards, rules, and guidelines seem to be limited. An adopted method is required in textile design area for product design today. In this context, from methodological perspective there is no solid theoretical framework which can assist the craftsman to consciously integrate their culture in designing products.

Ethnographic research is one of the Design Research (DR) methods that is a suitable for using in cultural design applications since it allows the designer to understand consumers, including how they act, what they want, and what their attitudes, perceptions, and behaviors are. The designer can discover unmet needs and understand the impact of a product within a specific context. Ethnographic research can enable products and services to meet more market and consumer needs, thereby reducing the risks of introducing a new product (Skaggs, 2010, p. 2).

The anthropological method of ethnography is usually defined as the description and explanation of the culture of a group of people (Wasson, 2002). Rodgers and Anusas (2008, p.1) argued that ethnography has recently been recognized as a creative process about discovering cultural patterns and developing models to explain those patterns. Used in this way, ethnography was employed as a front-end DR method to investigate everyday social life and culture as a context for innovation and creativity. Rodgers and Anusas confirmed that the commercial success of "People-Centered Design" approach has been proven and documented by many leading product development companies including Intel, Microsoft, BMW, and IDEO.

Many anthropologists and sociologists are employing ethnographic techniques to understand everyday product experiences and the processes of design (Costall and Dreier, 2006; Henare et al., 2007; Ingram et al., 2007). Furthermore, design researchers have adopted an ethnographic approach to study the organization of design and engineering processes (Bucciarelli 1994). Given, anthropology has its roots in cross-cultural understandings there is a distinct possibility for ethnography to be used to understand more about the processes of modern design pursuits. There is a need to present this wealth of activity concerning ethnography and design to a wider design audience in order to question and raise ideas concerning its applicability and usefulness to design education (Rodgers and Anusas, 2008, p.1). By being involved already from the first design iterations, or even before, ethnographic approaches can be applied during most stages of the design process, from exploration of the context of future users to testing of experience prototypes in situ. This lengthens the time span a design researcher can be involved in the design process (Segelström et al, 2009, p. 2).

This paper therefore presents a brief framework on what Design Science Research (DSR) is, the features and importance of ethnographic research in textile design and qualitative and quantitative approaches that can be used in ethnographic researches in textile and fashion sectors.

\section{DESIGN RESEARCH AND DESIGN SCIENCE RESEARCH}

The taxonomy of design knowledge and the generic model of design raise implications for Design Research (DR). These also involve understanding the kinds of knowledge that form a foundation for the research act. This, in turn, will reveal how knowledge moves from research into practice (Friedman, 2000, p.12). We might 
agree that scientific design refers to modern, industrialized design - as distinct from pre-industrial, craftoriented design - based on scientific knowledge but utilizing a mix of both intuitive and non-intuitive design methods. "Scientific design" is probably not a controversial concept, but merely a reflection of the reality of modern design practice (Cross, 2001, p.3)

Owen (2007, p.17) expressed that design thinking was in many ways the obverse of scientific thinking. Where the scientist shifted facts to discover patterns and insights, the designer invented new patterns and concepts to address facts and possibilities. Cross (2001, p.4) mentioned that Design as a Discipline, therefore, could mean design studied on its own terms, within its own rigorous culture.

In a world with growing problems that desperately need understanding and insight, there is also great need for ideas that can blend that understanding and insight in creative new solutions. DR is a methodology that involves the application of the principles and latest findings of science to the creative design and implementation of solutions to the problems of society. It is a way of recognizing, defining, and solving complex problems that is based on innovation and thrives on transparency. It takes a whole system, global, anticipatory and regenerative approach that fosters creative collaboration and synergy in the development of comprehensive solutions to both global and local problems (Gabel, 2010, p.12).

Cross (1999) defined that the field of DR would therefore fall into three main categories, based on people, process and product:

1-design epistemology (study of designedly ways of knowing)

2-design praxeology (study of the practices and processes of design)

3-design phenomenology (study of the form and configuration of artifacts) (Cross, 1999, p.6).

Until recently, the field of design has been an adjunct to art and craft. With the transformation of design into an industrial discipline came responsibilities that the field of design studies has only recently begun to address. Design is now becoming a generalizable discipline that may as readily be applied to processes, interfaces between media or information artifacts as to tools, clothing, furniture, or advertisements. To understand design as a discipline that can function within any of these frames means developing a general theory of design. This general theory shall support application theories and operational programs. Moving from a general theory of design to the task of solving problems involves a significantly different mode of conceptualization and explicit knowledge management than adapting the tacit knowledge of individual design experience (Friedman, 2003, p.519). The history of design survey must explicitly address the relevance and role that design history as a discipline can play in shaping practice and further study in the field (Lichtman, 2009, pp. 349).

Starting from early 2004, Design Science Research (DSR) is replacing DR name for the field. The difference is that DR is research into or about design whereas DRS is primarily research using design as a research method or technique (Vaishnavi and Kuecchler, 2004). According to March and Smith (1995) there are four outputs of DSR are constructs, models, methods and instantiations. The constructs are the conceptual vocabulary of a domain, models are a set of propositions or statements expressing relationships between constructs. Methods are a set of steps used to perform a task. Instantiations are the operationalization of constructs, model, and methods. Better theories are artifact construction as analogous to experimental natural science. Design Science Research (DSR) is a rapidly evolving field on these four outputs.

Schenk explained that for repurposing the taxonomy indicated below, capacity for further reflexivity on design thinking was being built into its construction. According to Schenk (2007) plans for future work also included adding to the design disciplines covered and exploring methods of cross-referencing through the taxonomy of design (Schenk, 2007). DSR focuses on four types of design contribution (improvement, invention, routine design and exaptation) regarding two parameters (solution and application domain maturity) (Gregor and Hevner, 2013, p.345).

DSR is judged first on its ability to clearly represent and communicate the new artifact design. Fig. 1 shows how and why the new solution differs from current solutions. Once the design improvement is described, then the artifact must be evaluated to provide convincing evidence of its improvement over current solutions. 


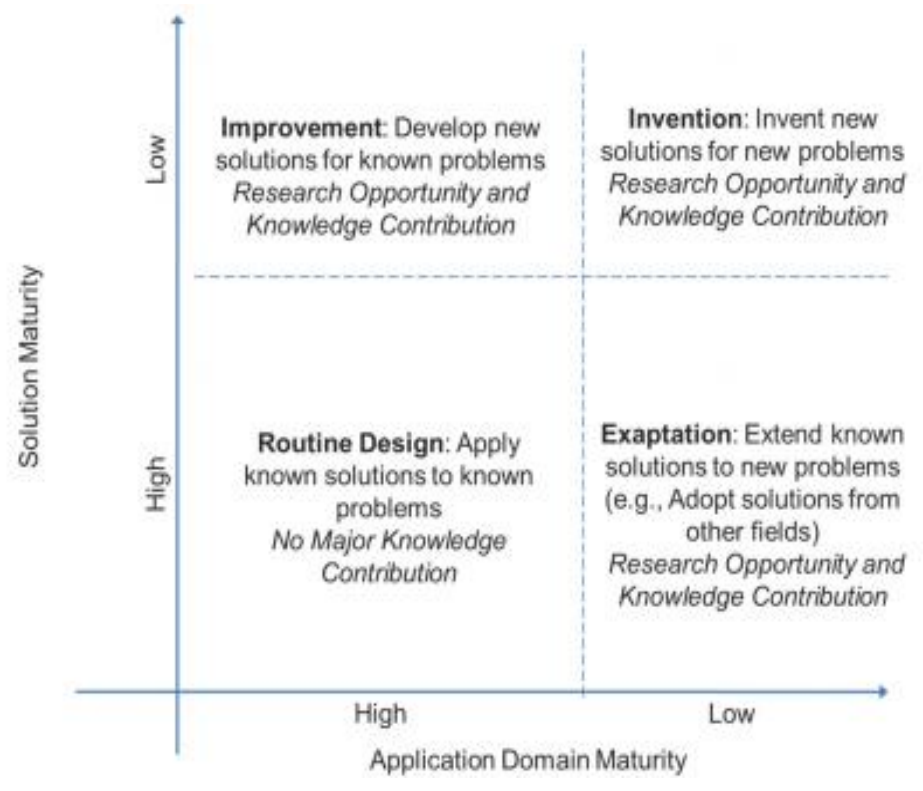

Figure 1-DSR Knowledge Contribution Framework (Gregor and Hevner, 2013, p.345)

Invention: New Solutions for New Problems: True invention is a radical breakthrough, a clear departure from the accepted ways of thinking and doing. Inventions are rare and inventors are rarer still (Gregor and Hevner, 2013, p.345). DSR projects in this quadrant will entail research in new and interesting applications where little current understanding of the problem context exists and where no effective artifacts are available as solutions. In fact, so little may be known about the problem that research questions may not even have been raised before. Research contributions in this quadrant result in recognizably novel artifacts or inventions. In this category appear artifacts where the idea of the artifact itself is new; for example, the first bicycle or the first decision support system (Gregor and Hevner, 2013, p.346).

Improvement: New Solutions for Known Problems: The goal of DSR in the improvement quadrant is to create better solutions in the form of more efficient and effective products, processes, services, technologies, or ideas. Researchers must contend with a known application context for which useful solution artifacts either do not exist or are clearly suboptimal. Researchers will draw from a deep understanding of the problem environment to build innovative artifacts as solutions to important problems. The key challenge in this quadrant is to clearly demonstrate that the improved solution genuinely advances on previous knowledge (Gregor and Hevner, 2013, p.346). Improvement DSR is judged first on its ability to clearly represent and communicate the new artifact design. Improvement may be in the form of positive changes in efficiency, productivity, quality, competitiveness, market share, or other quality measures, depending on the goals of the research (Gregor and Hevner, 2013, p.346).

Exaptation: Known Solutions Extended to New Problems: Original ideas often occur to individuals who have experience in multiple disciplines of thought. Such training allows interconnections and insights among the fields to result in the expropriation of artifacts in one field to solve problems in another field. Thus, we may face a research situation in which artifacts required in a field are not available or are suboptimal. However, effective artifacts may exist in related problem areas that may be adapted or, more accurately, exapted to the new problem context. In this quadrant are contributions where design knowledge that already exists in one field is extended or refined so that it can be used in some new application area (Gregor and Hevner, 2013, p.347). In exaptation research, the researcher needs to demonstrate that the extension of known design knowledge into a new field is nontrivial and interesting. The new field must present some particular challenges that were not present in the field in which the techniques have already been applied. In the exaptation quadrant, similarly to the improvement quadrant (Gregor and Hevner, 2013, p.347).

Routine Design: Known Solutions for Known Problems: Routine design occurs when existing knowledge for the problem area is well understood and when existing artifacts are used to address the opportunity or question. Research opportunities are less obvious, and these situations rarely require research methods to solve the given problem. In this quadrant is work that would not normally be thought of as contributing to research because existing knowledge is applied in familiar problem areas in a routine way. However, routine work may in some cases lead to surprises and discoveries but, in such cases, these discoveries will likely 
involve moving the research to one of the other quadrants (Gregor and Hevner, 2013, p.347). Glanville (1999) confirms that whether experimental or theory scientific research is a design activity. We design experiments, but we also act as designers in how we act in these experiments. Even though design knowledge arises in part from practice, however, it is not practice but systematic and methodical inquiry into practice-and other issues - that constitute design research, as distinct from practice itself. The elements of design knowledge begin in many sources, and practice is only one of them. (Friedman, 2003, p.512).

In more traditional quantitative techniques, context is treated as either a set of interfering variables that need controlling, known as noise in the data, and other controlled variables which are experimentally set up in order to seek for cause and effect relationships. In the more traditional qualitative approaches, context is treated as the socially constructed reality of a named group, or groups, of social agents and the key task of observation and analysis is to unpack the webs of meaning transformed in the social process whereby reality is constructed. In quantitative techniques, cause and effect are the main objects being searched for, while, in qualitative techniques, meaning in context is the most important framework being sought (Harvey and Myers, 1995). Because context is crucial to qualitative observations and analyses, techniques which explore contextual webs of meaning are important. The main body of techniques fall under the domain of an approach called ethnography (Harvey and Myers, 1995).

Some research traditions appear in related forms in more than one discipline, with the tradition originating in one discipline (e.g. ethnography originated in anthropology) and then being adapted for use in another discipline (e.g. some sociologists use ethnographic methods). Table. 1 presents 17 qualitative research traditions organized into three categories. The traditions within each category are related in that they study similar phenomena. Some focus on understanding the nature of lived experience (type I), others seek to understand cultural and social phenomena (type II) and still others seek to understand language and communication phenomena (type III) (Gall et al, 1996).

Table 1 Qualitative research traditions classified by type of phenomena investigated

\begin{tabular}{|c|c|}
\hline Research tradition & Involves the study of \\
\hline \multicolumn{2}{|r|}{ I. Investigation of lived experience } \\
\hline 1. Cognitive psychology & Mental structures and processes used by individuals in different situations \\
\hline 2. Life history & Individuals life experience from their perspective \\
\hline 3. Phenomenography & Individuals conceptualizations of reality \\
\hline 4. Phenomenology & Reality as it appears to individuals \\
\hline \multicolumn{2}{|r|}{ II. Investigation of society and culture } \\
\hline 1. Culturel studies & Oppressive power relationships in a culture \\
\hline 2. Emancipatory action research & $\begin{array}{l}\text { Practitioners self-reflective efforts to improve the rationality and justice of } \\
\text { their work }\end{array}$ \\
\hline 3. Ethnography & Characteristic features and patterns of a culture \\
\hline 4. Ethnomethodology & The rules that underlie everyday social interactions \\
\hline 5. Event structure analysis & The logical structures of social events \\
\hline 6. Symbolic interactionism & $\begin{array}{l}\text { The influence of social interactions on social structures and individuals self- } \\
\text { identity }\end{array}$ \\
\hline \multicolumn{2}{|r|}{ III. Investigation of language and communication } \\
\hline 1. Ethnographic content analysis & The content of documents in cultural perspective \\
\hline 2. Ethnography of communication & How members of a cultural group use speech in their social life \\
\hline 3. Ethnoscience & A culture's semantic systems \\
\hline 4. Hermeneutics & The process by which individuals arrive at the meaning of a text \\
\hline 5. Narrative analysis & Organized representations and explanations of human experience \\
\hline 6. Semiotics & Signs and the meanings they convey \\
\hline 7. Structuralism & The systemic properties of language, text, and other phenomena \\
\hline
\end{tabular}

As the result of the postmodern society, explosion of the Internet with its reach into all aspects of people's lives has accelerated the move of information technologies out of the workplace and into homes, recreational environments, and other non-work-related settings causing a recent trend for the ethnographic perspective in design. Given the variety of methods and data collection tools open to ethnographers, ethnography can be malleable to suit a particular research agenda, provided it is made clear how the researcher is using the approach in his/her particular research undertaking. The underlying elements of ethnography are the specificity of its study of a particular culture/sub-culture or population, and the use of observation in amassing field and 
contextual notes pertaining to (and used in the analysis and interpretation of) that culture/sub-culture or population (Hogan et al, 2011, p.36).

\section{ETHNOGRAPHIC DESIGN RESEARCH}

Etymologically, "ethnography" comes from the Greek words ethnos (nation, people) and graphia (writing) and means therefore a written presentation of a people or a population, which seeks to identify and interpret its universal traits (those shared with other populations), but also the particular characteristics, specific only for the group studied (Bălan, 2011). Literally, ethnography translates as "drawing the social group". In other words, ethnography is a specific type of illustration of a cultural or social life, world or experience (Agafonoff, 2006). The roots of ethnography lie in cultural anthropology, with its focus on small-scale societies and the original central concept remains paramount today; that is a concern with the nature, construction and maintenance of culture. Ethnographies are always informed by this concept as ethnographers aim to look beyond what people say to understand the shared system of meanings we call "culture" (Goulding, 2005).

The first anthropologist to adopt the ethnographic research method was Bronislaw Malinowski, who in 1922 published his now famous book Argonauts of the Western Pacific. This book was based on Malinowski's fieldwork among the Trobriand Islanders (Harvey and Myers, 1995).

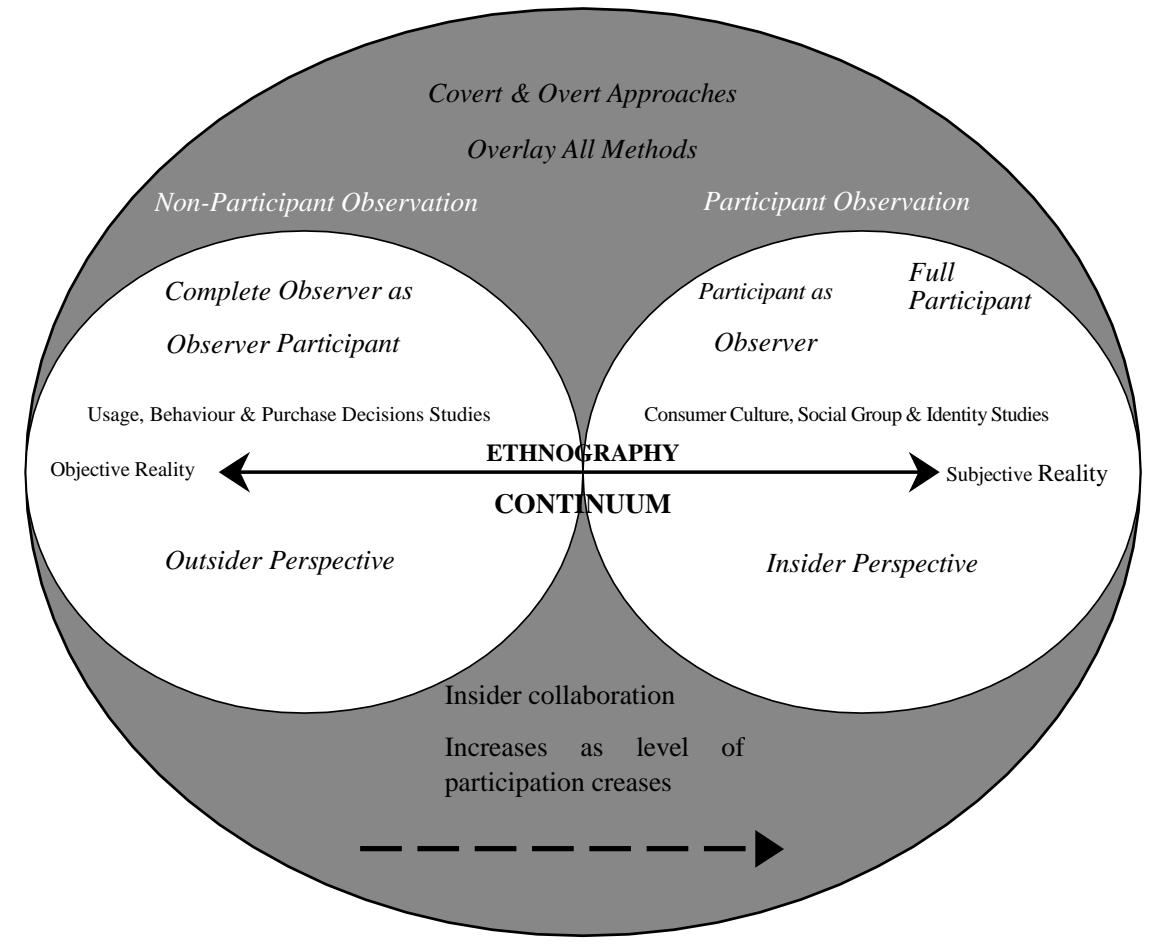

Figure 2- A multi-dimensional framework for applied ethnography (Agafonoff, 2006, p.118)

Ethnography is a multi-faceted research tool with a diversity of configurations and applications (Fig.2). It is misleading to think of ethnography as purely non-participant observational research, as so many people in market research tend to do. However, it is also incorrect to think that "authentic" ethnography is purely longitudinal participant observation research of the anthropological nature. In truth, both methods represent branches of the same tree - each designed for specific purposes.

Non-participant observation methods: One of the most obvious applications of ethnography to market research is to use it as a tool to understand consumer purchase behavior. Market researchers have wrangled with this beast ever since the supermarket aisle was first invented. In the beginning, researchers attempted to accompany shoppers on shopping expeditions and take detailed observational notes on their behavior and purchase decisions. In more recent times market researchers have videoed the shopping expedition (Agafonoff, 2006, p.119).

Participant observation methods: The question of how best to conduct over to participant observation research has not yet been properly debated in market research. Consequently, many misconceptions have taken root around best approach. This will relax subjects. They may even see you as a "try-hard" or worse, 
trying to deceive them. Subjects are more interested in your frankness and confidence as a researcher, and that you are upfront as to who you are and what you are doing. Most crucially, they need to know that you are intrinsically interested in them, and their world. You can do this by displaying empathy and understanding of who they are and what they value (Agafonoff, 2006, p.120).

The principal common characteristics of ethnography are:

1 - A focus on a discrete location, event(s) or setting.

2- A concern with the full range of social behavior within the location, event or setting.

3-The use of a range of different research methods which may combine qualitative and quantitative approaches but where the emphasis is upon understanding social behavior from inside the discrete location, event or setting.

4- An emphasis on data and analysis which moves from detailed description to the identification of concepts and theories which are grounded in the data collected within the location, event or setting.

5- An emphasis on rigorous or thorough research, where the complexities of the discrete event, location or setting are of greater importance than overarching trends or generalizations (Pole and Morrison, 2003).

Ethnographic research offers several advantages. For example, the use of participant observation enables ethnographers to "immerse" themselves in a setting, thereby generating a rich understanding of social action and its subtleties in different contexts. Participant observation also gives ethnographers opportunities to gather empirical insights into social practices that are normally "hidden" from the public gaze. Additionally, since it aims to generate holistic social accounts, ethnographic research can identify, explore, and link social phenomena which, on the surface, have little connection with each other. Owing to the relatively long periods of time ethnographers spend talking to participants and observing actions, it can be difficult to secure repeated access, especially if institutional gatekeepers are concerned that the research may cast their organization in a poor light. Comprehensively recording the multifaceted nature of social action that occurs within a clinic or ward is a difficult task, as a range of temporal, spatial, and behavioral elements need to be documented. In addition, the unpredictability of social (and clinical) life often means that ethnographers have to be flexible, patient, and persistent in their work, as data collection activities can be disrupted or access withdrawn as local circumstances and politics change (Reeves, 2008).

\section{ETHNOGRAPHIC DESIGN RESEARCH IN TEXTILE AND FASHION}

Textiles and apparel or fashion manufacturers face every day with increased competition. Growth of Designer and Brand names becomes pervasive since it has to be supported by tremendous advertising. Retailing proves to be overstored. The industrial and business context makes textile design rather different from the happy and beautiful images of models walking through the catwalk. The textile and fashion companies with well-organized management structures and talent management practices are searching for competitive advantage. The professionals in the sector are searching for effective creativity. Textile and fashion companies are key players in the stock market and parent groups of brands are not dissimilar to international companies that seek trade and financial investment to support their growth objectives. Rather than design being conducted by isolated creative individuals who continually push the boundaries of taste and public acceptability, fashion design here has essential ties with its organizational and inter-organizational business setting. Design is also tied to production and forever mindful of potential problems that an idea might encounter at the production phase. This makes a core component of fashion design 'specification work' and-like such work in other industrial contexts-specifications are rarely worked up from scratch.

In contrast then to many intuitive notions of fashion design, time-critical and season-sensitive design proves to be the focus of both industries. Whole manufacturing process begins as an activity involving the collection, manipulation and management of multiple forms of data about products, suppliers and customers. Fashion marketing is the entire process of researching, planning, promoting and distributing raw materials, apparel, and accessories. It involves everyone in the fashion industry and occurs through the entire channel of distribution.

In couture or ready-to-wear industries design makes a core component of fashion and textile business. All the design work is done as much with databases, records, sources of information and intelligence, as it is with artist's sketch pad or with CAD/CAM-indeed. Today the industry now endeavors to find out what customers will want to buy through research and then tries to develop the products to answer these needs. Fashion industry executives continually learn about consumer behavior to get clues as to what products consumers might need or want to buy in the future.

Design activity breaks down into "buying trips", "product specification", "sample assessment", "pattern 
production", "textile design", "sizing and grading", "packaging and labelling" and so forth. All of these activities have their own distinct location within the organization, their own specialized persons and supporting computer systems, and many are regarded as being 'technological' in nature. Through a detailed study of the workplace, ethnographic research can uncover many of the means by which cooperative work is coordinated by members: This can often be suggestive of overall metaphors which can guide application development and present intelligible interface objects. It is also vital to appreciate the socially distributed and variable nature of design activities. In fact, there is no single activity which organization members refer to as 'design' and no single organizational locus for it.

Furthermore, in the mass-market commercial context that textile and fashion companies operate in, detailed knowledge of its customers and of the acceptability of current and past stock options become essential to reducing business risks and maximizing the chances of satisfactory sales on items. The results from an ethnographic study can often inform developers and implementers of the most appropriate settings for the technology they are developing or have developed. Such results may contradict intuitions about the usefulness of applications and an application may tum out to be useful in a setting not anticipated by its developers. This use of ethnography may be particularly prominent when development work is advanced or design decisions are so entrenched that it is impractical to change or reverse them.

These results are a first step towards an improved understanding of the behavior of designers when facing non-routine situations. Through this understanding more appropriate ways of assisting designers can be developed as we continue to explore how design methods can support designers in dealing with uncertainty. Two particular aspects are important. First, there is a need for research to explore the relationship between the designer's perceived source of uncertainty and the way in which a specific design method might allow for an effective response to that situation. A framework is needed to analyze specific non-routine situations and characterize them according to the immediate needs of the designer. Second, there is a need to encourage the designer to take a more comprehensive look at non-routine situations by reflecting on his own contribution to the situation. This limited study implies that designers focus primarily on issues related to the task and to the social context. If one could enable designers to reflect more effectively on the determining factors in nonroutine situations, it may be possible to provide them with design methodologies that would support them in more appropriate ways. As stated earlier, a promising approach seems to be to develop a web-based, interactive system which integrates the findings of this and future studies into designer-centered design methodology. Such a system should as its objectives:

1) stimulate designers to reflect upon non-routine situations and motivate them to use appropriate methodologies,

2) enable the designer to quickly find an appropriate methodology, and

3) stimulate discussion about design methodology within a web-based community of designers and researchers (Daalhuizen et al, 2009, p.156-157).

While "good" design sense is often the result of years of training and experience, becoming aware of the rationale behind such choices is not only interesting, but, if well documented and openly disseminated, can benefit the information visualization community as a whole. (Van de Moere and Purchase, 2011, p.369). A standardized framework would allow industry and academia to quickly develop test sequences, more efficiently organize and retrieve data and make better use of a scientific database approach to experimental results and so on. Using some form of modular procedure would give researchers the ability to concentrate on the detail and production of experiments rather than the currently time consuming need to develop a new research protocol for each test individually. Realizing a modular solution would also allow industry to implement a research based strategy over their existing operating protocols with the minimum investment and would give a foundation for comparability between academic and industrial research. Creating a large scale pool of linked experiments would allow meaningful comparisons to be made between lab based and industrial tests, different cultures and facilities as well as many other key areas (Cash et al., 2009).

Symbols enable humans to produce culture and transmit complex histories. We imbue meaning into everything, extending into the wider social worlds in which we exist. Through participant observation research, we can gain access to these symbols and meanings (Becker, 1982). As a symbolic interactionist, I see the social world as a dynamic dialectical web (Perinbanayagam, 1983). As humans we are "connected" to "others" (Cooley, 1902). For this reason, I encourage market research clients to put aside their anxieties about commissioning longitudinal ethnographic studies of consumer subcultures and consider extending past ad hoc applications. I envisage a time when ethnography sits at the nexus between the consumer world and the corporation. 
Many key activities are essentially cooperative. While individuals may have their own distinct responsibilities, this comprises a working division of labor constituted by an awareness of each other's work and a readiness to help when required. Buyers and garment technologists cooperate on specifications, the sense given to 'accurately following them', what might be wrong with problematic garments or suppliers and what can be done to correct affairs. Technologists cooperate in assembling 'specs' and in retrieval of likely candidates for modification. Ethnographic work can be used as a resource for defining and redefining research agendas in textile product development process. Fashion design is no one single activity and bears scant resemblance to any abstract notion of what design might be all about. The results from an ethnographic study can often inform developers and implementers of the most appropriate settings for the technology they are developing or have developed. Such results may contradict Intuitions about the usefulness of applications and an application may tum out to be useful in a setting not anticipated by its developers. This use of ethnography may be particularly prominent when development work is advanced or design decisions are so entrenched that it is impractical to change or reverse them.

\section{CONCLUSION}

In anthropology, ethnography developed as way to explore the everyday realities of people living in small scale, non-western societies and to make understandings of those realities explicit and available to others. The approach relied on the ability of all humans to figure out what is going on through participation in social life. Its techniques bear a close resemblance to the routine ways people make sense of the world in everyday life. The research techniques and strategies of ethnography developed and evolved over the years to provide ways for the ethnographer to "be present" for the mundane, the exceptional, and the extraordinary events in people's lives (Blomberg, 2002). The primary advantage of ethnography is its observational technique that allows researcher to record the behavior as it occurs. Furthermore, it will uncover and thoroughly describe the phenomena in a community. The last advantage of ethnography research is to understand the phenomenon under study from the perspective of those being studied. Therefore, the finding is more real than a research that manipulates variables by using external experiments (Nurani, 2008).

No other research tradition matches the ability of ethnography to investigate the complex phenomenon known as culture. Its holistic orientation enables a skillful researcher to identify diverse elements of a culture and weave them into coherent patterns. Ethnographers generally take an emic perspective, which means that the culture members own perceptions and language categories are used to describe and explain the culture. While this perspective helps the reader understand the culture as a unique social reality, it does not provide a basis for discovering laws of social life. An etic perspective, in which the researcher develops her own categories for understanding a culture, might provide a better basis for cross cultural studies and the discovery of crosscultural laws. However, these categories might distort our understanding of any particular culture. Another unresolved issue is whether ethnography should subscribe to the goal of the natural sciences to develop universal laws or to the goal of the humanities to understand the unique and particular case (Gall et al., 1996).

All global corporate brands, textiles and apparel companies included, are drawing upon ethnographic researchers of all types - journalists, writers, photographers and filmmakers, to bring consumer worlds to life and subsequently being disseminated across the organization. Textile and fashion companies should take advantage of ethnographic design collaborations in order to understand emergent culture of the consumer groups and meaning in peoples' lives. If textile and fashion marketers recognize that consumption is fundamental to all human experience, then they will see the power of ethnographic research not just for the tactical insights that it can deliver, but also for its broader portrayal of the evolving consumer landscape.

\section{REFERENCE LIST}

Nick, A. (January 01, 2006). "Adapting Ethnographic Research Methods to Ad Hoc Commercial Market Research". Qualitative Market Research: an International Journal. 9, 2, 115-125.

Alexander, C. (1964). Notes on the Synthesis of Form. Harvard University Press, Oxford.

Bălan, S. (2011). "Ethnographic Method in Anthropological Research". Cogito. vol. 3.

Blomberg, J., Burrell, M. and Guest, G. (2002). An Ethnographic Approach to Design. New Jersey: Lawrence Erlbaum Associates.

Breu, Marlene, \& Marchese, Ronald. (1998).Brokers of Textile Traditions: The Case of the Shopkeepers in Turkey. DigitalCommons@University of Nebraska - Lincoln. 
Britt, H. (2012). "The Art of Textile Design Research: Educator Approaches to Creative Practice the Art of Research". The Art of Research IV. Finland.

Bucciarelli, L. L. (1994). Designing Engineers. Cambridge, Mass: MIT Press.

Cash, P., Hicks, B. and Culley, S. (2009). "The Challenges of Ethnographic Design Research: A Methodological Framework for Conducting Observational Experiments". In International Conference on Engineering Design, ICED'09, 2009-08-24 - 2009-08-27, Stanford University, Stanford, CA.

Costall, A., \& Dreier, O. (2006). Doing Things with Things: The Design and Use of Everyday Objects. Aldershot: Ashgate.

Cross, N. (1999). "Design Research: A Disciplined Conservation”. Design Issues. Vol. 15.

Cross, N. (2001). "Designerly Ways of Knowing: Design Discipline versus Design Science". Design Issues. Vol. 17.

Evbuomwan, N. F. O., Sivaloganathan, S. and Jebb, A. (1996). "A Survey of Design Philosophies, Models, Methods and Systems". Proceedings of the Institution of Mechanical Engineers, Part B: Journal of Engineering Manufacture.

Friedman, K. (2003). "Theory Construction in Design Research: Criteria: Approaches, and Methods." Design Studies. Vol. 24.

Friedman. K. (2000). "Creating Design Knowledge: from Research into Practice”. IDATER 2000 Conference. Loughborough.

Gabel, M. (2010). Designing A World That Works For All. USA: Gabel Graphics.

Gall, M. D. Borg, W. R. and Gall, J. P. (1996). Educational Research. USA: Longman Publishers.

Glanville, R. (1999). “Researching Design and Designing Research”. Design Studies. Vol. 15.

Goulding, C. (2005). Grounded theory, ethnography and phenomenology: A comparative analysis of three qualitative strategies for marketing research. European journal of Marketing, Vol. 39.

Gregor, S. and Hevner, A. R. (2013). "Positioning and Presenting Design Science Research for Maximum Impact". MIS Quarterly. Vol. 37.

Harvey, L. J., and Myers, M. D. (1995). "Scholarship and Practice: The Contribution of Ethnographic Research Methods to Bridging the Gap". Information Technology \& People. Vol. 8.

Henare, A. J. M., Holbraad, M., \& Wastell, S. (2007). Thinking through Things: Theorising Artefacts Ethnographically. London: Routledge.

Shove, E. (2007). The design of everyday life. New York, NY: Berg.

Lichtman, S. A. (2009). "Reconsidering the History of Design Survey". Journal of Design History. Vol. 22.

Lin, R. T. (2007). "Transforming Taiwan Aboriginal Cultural Features into Modern Product Design: A Case Study of a Cross- Cultural Product Design Model". International Journal of Design. Vol. 1.

March, S., and Smith, G. 1995. "Design and Natural Science Research on Information Technology," Decision Support Systems. (15), pp. 251-266.

Moalosi, R., Popovic, V. \& Hickling-Hudson, A. (2007). "Culture-Orientated Product Design". International Association of Societies of Design Research. Hong Kong.

Nurani, L. (2008). "Critical Review of Ethnographic Approach". Journal Sosioteknologi Edisi 14 Tahun, 7.

Owen, C. (2007). "Design Thinking: Notes on Its Nature and Use”. Design Research Quarterly. V: 2 N:1, pp:134.

Pole, C. and Morrison, M. (2003). Ethnology for Education. Berkshire. GBR: McGraw-Hill Education.

Pycock, J. ve Bowers, J. (1996). "Getting Others To Get It Right: An Ethnography of Design Work in the Fashion Industry”, in Proc.CSCW'96, Boston, MA. ACM Press, pp. 219-228.

Reeves, S., Kuper, A. and Hodges, B.D. (2008). "Qualitative Research Methodologies: Ethnography". BMJ. Vol. 337. 
Rodgers P.A. and Anusas M. (2008). "Ethnography and Design, International Conference On Engıneering and Product Design Education", Unıversitat Politecnica De Catalunya, Barcelona, Spain, 4 \& 5 September 2008.

Schenk, P. (2007). "Developing a Taxonomy on Drawing for Design". International Association of Societies of Design Research. Hong Kong.

Segelström, F., Raijmakers, B., \& Holmlid, S. (2009). "Thinking and Doing Ethnography in Service Design". IASDR, Rigor and Relevance in Design. Seoul.

Skaggs, P. (2010). "Ethnography in Product Design-Looking for Compensatory Behaviors". Journal of Management and Marketing Research.

Stolterman, E. Mcatee, J. Royer, D. and Thandapanı, S. (2008). "Designedly Tools". In Undisciplined! Design Research Society Conference. Sheffield, UK.

Terzidis, K. (2007). "The Etymology of Design: Pre- Socratic Perspective". Design Issues. Vol. 23.

Vaishnavi V. and Kuechner W. (2004) "Design Science Research in Information Systems," January 20, 2004; last updated: October 23, 2013 http://desrist.org/desrist/content/design-science-research-ininformation-systems.pdf

Wasson, C., "Collaborative Work: Integrating the Roles of Ethnographers and Designers", in S. Squires and B. Byrne (Editors), Creating Breakthrough Ideas: The Collaboration of Anthropologists and Designers in the Product Development Industry. Bergin \& Garvey, Westport, Connecticut, 2002, pp. 71 - 90. 